This item was submitted to Loughborough's Research Repository by the author.

Items in Figshare are protected by copyright, with all rights reserved, unless otherwise indicated.

\title{
Maturity method to predict the evolution of the properties of sprayed concrete
}

PLEASE CITE THE PUBLISHED VERSION

http://dx.doi.org/10.1016/j.conbuildmat.2014.12.038

\section{PUBLISHER}

(c) Elsevier Ltd

\section{VERSION}

AM (Accepted Manuscript)

\section{PUBLISHER STATEMENT}

This work is made available according to the conditions of the Creative Commons Attribution-NonCommercialNoDerivatives 4.0 International (CC BY-NC-ND 4.0) licence. Full details of this licence are available at: https://creativecommons.org/licenses/by-nc-nd/4.0/

\section{LICENCE}

CC BY-NC-ND 4.0

\section{REPOSITORY RECORD}

Galobardes, Isaac, Sergio H. Cavalaro, Chris I. Goodier, Simon A. Austin, and Angel Rueda. 2019. "Maturity Method to Predict the Evolution of the Properties of Sprayed Concrete". figshare.

https://hdl.handle.net/2134/17495. 


\title{
MATURITY METHOD TO PREDICT THE EVOLUTION OF THE PROPERTIES OF SPRAYED CONCRETE
}

\author{
Isaac Galobardes ${ }^{\mathrm{a} *}$, Sergio H. Cavalaro ${ }^{\mathrm{a}}$, Chris I. Goodier ${ }^{\mathrm{b}}$, Simon Austin ${ }^{\mathrm{b}}$, Ángel Rueda ${ }^{\mathrm{c}}$
}

${ }^{a}$ Department of Construction Engineering, Universitat Politècnica de Catalunya, UPC, Jordi Girona 13, 08034 Barcelona, Spain.

${ }^{b}$ School of Civil and Building Engineering Loughborough University, Loughborough, Leicestershire LE11 3TU, United Kingdom.

${ }^{c}$ R\&D Department, Industrias Químicas del Ebro S.A., Polígono de Malpica calle D 97, 50016 Zaragoza, Spain.

* Corresponding author. Tel.: +34-93-401-7825; fax: +34-93-401-1036; e-mail:

isaac.galobardes@upc.edu

\begin{abstract}
The maturity method provides a simple approach for assessing the strength evolution of concrete.

Although it is already used in the precast industry, no reported applications with sprayed concrete may be found in the literature. Such concrete presents singular characteristics due to the spraying process and, in some cases, due to the introduction of accelerators that modify the kinetics of cement hydration.

Consequently, the traditional equations that relate the evolution of mechanical properties and the maturity index might not apply in this case. The objective of this study is to adapt the maturity method to sprayed concrete. An experimental program was conducted with 24 concrete mixes sprayed in laboratory and tested for the evolution of temperature and compressive strength. An alternative equation was proposed to relate the maturity index and the mechanical properties. Subsequently, finite element models were developed to generalize the maturity curves considering the local design parameters.
\end{abstract}

Keywords: sprayed concrete; maturity method; control method; compressive strength; evolution of temperature 


\section{Introduction}

The maturity method provides a relatively simple approach for assessing the in-situ strength evolution of concrete during construction. It relies on the measured temperature history of the concrete to estimate the maturity index that is then related with the strength development during the curing period. For each concrete mix composition, the relationship between a mechanical property and the maturity index can be established via trial mixes subjected to controlled conditions.

The method has been widely used in applications such as concrete pavements or precast concrete to improve productivity by, for instance, minimising the curing time (Carino, 2001; $\mathrm{H}$. Beushausen, 2012; Kaszyñska, 2002; Waller et al., 2004). However, according to the literature, there have been no reported examples of applications with sprayed concrete. This special type of concrete is pumped and sprayed over vertical or top surfaces, resisting the self-weight and the loads applied as soon as the element is executed. In some applications, accelerators are added to the mixture in order to speed up the setting and the short-term evolution of mechanical properties. For that reason, the early strength control is a key element that might affect the productivity and the safety in the worksite (Dimmock, 2004; Zangerle, 1998).

The maturity method, adapted to this particular form of concrete construction, would help engineers decide when the construction advance could be done safely. Furthermore, it would be a helpful alternative to the two traditional tests used to measure the compressive strength evolution of the sprayed concrete at early ages - the penetration needle test and the stud driving method (European Committee for Standarization, 2007). In that sense, the time to obtain results and the number of people working under a risky condition in a poor environment (i.e. tunnelling) could be reduced (Austin, 1996).

Several reasons explain the difficulties associated with the implementation of the maturity method for the quality control of sprayed concrete. On one hand, the conventional equations used to relate the evolution of mechanical properties and the maturity index might not apply to 
mixes with accelerators. On the other hand, changes in the characteristics of the support over which the material is sprayed may affect the heat transfer of the concrete layer (Aggoun, 2006; Liwo,2006). Therefore, the calibrations of the maturity index for a certain condition might not be generalized to the high variability of conditions found in practice.

The aim of this study is to propose a methodology for the quality control of sprayed concrete based upon the maturity method that overcomes the difficulties mentioned previously. Accordingly, an experimental programme was conducted involving the spraying of 24 different concrete mixes, which were then characterized for the evolution of temperature and compressive strength. The relationship between these two parameters were used to propose an alternative equation that relates the maturity index and the evolution of mechanical properties for sprayed concrete with accelerators. Subsequently, an approach using finite element models (FEM) was developed with the aimed of adapting the maturity curves obtained in laboratory to the local conditions (such as layer thickness and the type of ground support) found in the worksite. The theoretical and empirical findings are presented, culminating in a description of the proposed in-situ application.

\section{The Maturity method}

The Nurse-Saul function (Eq. 1) is commonly used (Carino, 2001) to assess the maturity index (M), taking into account the the evolution of temperature $(T)$ over time $(t)$ and the datum temperature $\left(T_{o}\right)$. This last parameter, which is equal to $-10{ }^{\circ} \mathrm{C}$ in different studies (Carino, 2001), represents the minimum temperature that permits the chemical reaction of cement hydration.

$$
M=\sum_{0}^{t} T-T_{o} \cdot \Delta t
$$

This index $M$ may be related to the compressive strength $(S)$ using the Plowman's logarithmic equation (Plowman, 1956). This presents two parameters, $a$ and $b$, that are the strength for 
maturity index equal to 1 and the slope of the line, respectively. The relationship between both these parameters shown in Eq. 2 gives the maturity curves.

$$
S=a+b \cdot \log (M)
$$

The latter is capable of estimating the strength evolution of conventional concrete as observed in various studies (Sofi et al., 2012; Carino, 2001). However, sprayed concrete often has particular characteristics that are not considered in Plowman's equation. The addition of accelerators very common in sprayed concrete for tunnelling applications - changes the chemical reactions produced during the hydration of cement (Julliand, 2009; Galobardes, 2013). These chemical changes alter the development of the mechanical properties of the sprayed concrete at very early ages, which consequently requires a modified relationship between the compressive strength and the maturity index.

Moreover, maturity curves are based upon pre-determined calibrations of the time-temperaturestrength relationship development, determined in laboratory tests. These conditions, however, are different from those found on a construction site, particularly in tunnelling applications. Consequently, maturity curves for sprayed concrete are usually obtained experimentally by spraying in the laboratory moulds with a thickness of $150 \mathrm{~mm}$ as described by the standard UNE-EN 14488-2:2007 (European Committee for Standarization, 2007). In underground construction, the thickness of concrete is chosen due to structural reasons - the weaker the ground support, the thicker the lining (considering the same concrete compressive strength). Furthermore, the ground support in a tunnel has different thermal and mechanical properties than a metallic mould used in a laboratory. These variations cause changes in the evolution of temperature inside the concrete, and therefore variations in the maturity curves, due to heat transfer between the different materials.

This heat transfer, governed by a diffusion phenomenon, is the exchange of energy through the boundary between two systems. When an object is at a different temperature from another body or its surroundings, heat flows until the body and its surroundings reach the same temperature. 
Heat transfer always occurs from a region of high temperature to an adjacent region of lower temperature, as described by the second law of thermodynamics (Carslaw, 1959). In the case of underground construction, thermal conduction is the fundamental heat transfer mode that occurs between the concrete and the ground, whereas convection is the one that occurs between the concrete and the atmosphere. This phenomenon is different in the specific case of spraying into a mould (Figure 1).
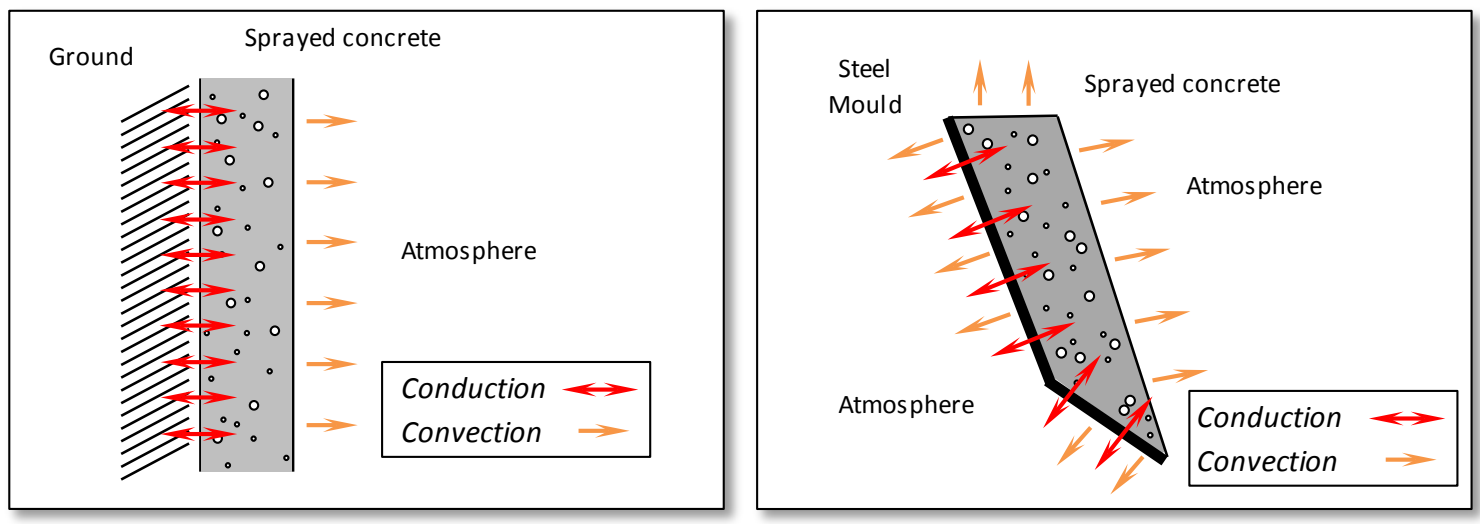

Figure 1- Heat transfer modes in a tunnel a) and for a sprayed mould b)

An experimental programme was designed to consider this phenomenon and propose a methodology to perform the maturity method on the sprayed concrete. This involved tests in laboratory conditions to obtain the maturity curves and finite element modelling in order to adapt these curves to the real conditions.

\section{Methodology}

This section presents the materials to produce the mixes and their composition, the spraying process and the test methods considered in the study. It also explains the FEM developed in order to generalize the experimental results to the real case conditions.

\subsection{Materials and composition of mixes}

The cements CEM I 52.5 R (CEM I) and CEM II/A-L 42.5 R (CEM II) were used in the study. Their main characteristics are presented in Table 1. The high proportion of clinker of CEM I allows quick setting of the concrete and, therefore, a high compressive strength at early ages. 
Although it is still used in sprayed concrete, the European tendency is to favour blended cements for environmental reasons. In order to reduce the $\mathrm{CO}_{2}$ emissions during the production of cement, several European countries apply cements type II, which include additions in order to reduce the amount of clinker (S. Juan, 2007; Scheider, 2011). Following this trend, this study also considered CEM II, which presents a substitution of approximately $20 \%$ of clinker by limestone powder filler. This filler is common in Spain and contributes to reducing the setting time of concrete (Y. Zhang, 2008).

Table 1- Main characteristics of the cements used

\begin{tabular}{|l|c|c|}
\hline \multicolumn{1}{|c|}{ Cement } & CEM II/A-L 42,5 R & CEM I 52,5 R \\
\hline Clinker (\%) & 88 & 98 \\
\hline Limestone & 10 & - \\
\hline Minor component & 2 & 2 \\
\hline Sulphate, $\mathrm{SO}_{4}^{2-}(\%)$ & 3.3 & 3.4 \\
\hline Chlorides, $\mathrm{Cl}^{-}(\%)$ & 0.01 & 0.04 \\
\hline Blaine specific surface $\left(\mathrm{cm}^{2} / \mathrm{g}\right)$ & 3900 & 4600 \\
\hline Soundness Le Chatelier $(\mathrm{mm})$ & 0.5 & 0.5 \\
\hline
\end{tabular}

In total, three families of alkali-free accelerators were investigated, each composed of two formulations of accelerators chemically based on hydroxysulphate of aluminium $\left(\mathrm{Al}\left(\mathrm{SO}_{4}\right)_{\mathrm{x}}(\mathrm{OH})_{3-2 \mathrm{x}}\right)$. These accelerators were selected in order to cover the variety usually applied in practice and regarding environmental aspects, which eradicate the use of alkali accelerators. Table 2 summarizes the characteristics of the accelerators used.

Table 2- Characteristics of the accelerators

\begin{tabular}{|c|c|c|c|c|c|c|}
\hline Family & Accelerator & $\begin{array}{c}\text { Dry matter } \\
(\%)\end{array}$ & $\begin{array}{c}\text { Molar ratio } \\
{\left[\mathrm{SO}_{4}^{2-}\right]\left[\mathrm{OH}^{-}\right]}\end{array}$ & $\begin{array}{l}\text { Molar ratio } \\
{\left[\mathrm{Al}_{3}{ }^{+}\right][\mathrm{OH}]}\end{array}$ & Stabilizer & $\begin{array}{c}\mathrm{pH} \\
\left(20^{\circ} \mathrm{C}\right) \\
\end{array}$ \\
\hline \multirow{2}{*}{1} & AF-1.1 & 38 & 0.6 & 0.8 & Inorganic acid & 3.3 \\
\hline & AF-1.2 & 48 & 0.8 & 1.0 & Polycarboxylic acid & 3.1 \\
\hline \multirow{2}{*}{2} & AF-2.1 & 39 & 3.4 & 2.6 & Inorganic silicate & 2.5 \\
\hline & AF-2.2 & 42 & 2.8 & 2.2 & Inorganic silicate & 2.6 \\
\hline & AF-3.1 & 30 & 3.0 & 2.5 & Polycarboxylic acid & 2.7 \\
\hline & AF-3.2 & 30 & 4.5 & 4.0 & Polycarboxylic acid & 2.7 \\
\hline
\end{tabular}

For each one of the, two doses by cement weight (\%bcw) were studied, as indicated in Table 3. These were established according to the recommendations of the supplier and the results of the initial/final setting time from former studies (Galobardes, 2009; Galobardes, 2010). 
Table 3- Doses considered (\%bcw)

\begin{tabular}{|c|c|c|}
\hline Family & Low Dose & High dose \\
\hline 1 & 5 & 7 \\
\hline 2 & 5 & 7 \\
\hline 3 & 9 & 11 \\
\hline
\end{tabular}

The base concrete mix composition consisted of $425 \mathrm{~kg} / \mathrm{m}^{3}$ of cement, $380 \mathrm{~kg} / \mathrm{m}^{3}$ of fine limestone sand $(0-2 \mathrm{~mm}), 900 \mathrm{~kg} / \mathrm{m}^{3}$ of coarse limestone sand $(0-5 \mathrm{~mm})$ and $380 \mathrm{~kg} / \mathrm{m}^{3}$ of limestone gravel $(5-12 \mathrm{~mm})$ with a water-to-cement ratio of 0.45 . Furthermore, a polycarboxylic superplasticizer was added to increase both the fluidity and the workability of the concrete. It has an approximate density at $20{ }^{\circ} \mathrm{C}$ of $1.04 \mathrm{~g} / \mathrm{cm}^{3}$, pH equal to 5.0 and a $37.0 \%$ of dry residue. This superplasticizer content was $1 \%$ bcw for each mix studied, as recommended by the manufacturer and following typical sprayed concrete composition for tunnelling construction. A ready mix plant that also produced the concrete for a new underground line in Barcelona supplied the base concrete. Note that certifications from the supplier were required to verify the mix design.

The total combination of variables yielded 24 mixes of sprayed concretes to be tested, as summarized in Table 4. The nomenclature defined for the mixes is formed by the name and the dose of the accelerator followed by the simplified indication of the cement type. All terms are separated by the symbol '_.'

Table 4- Sprayed concrete mixes

\begin{tabular}{|c|c|c|c|c|}
\hline Family & Type of accelerator & Dose (\%bcw) & Type of cement & Mix reference \\
\hline \multirow{8}{*}{1} & \multirow{4}{*}{ AF-1.1 } & 5 & \multirow{2}{*}{ CEM I } & AF-1.1_5_I \\
\hline & & 7 & & AF-1.1_7_I \\
\hline & & 5 & \multirow{2}{*}{ CEM II } & AF-1.1_5_II \\
\hline & & 7 & & AF-1.1_7_II \\
\hline & \multirow{4}{*}{ AF-1.2 } & 5 & \multirow{2}{*}{ CEM I } & AF-1.2_5_I \\
\hline & & 7 & & AF-1.2_7_I \\
\hline & & 5 & \multirow{2}{*}{ CEM II } & AF-1.2_5_II \\
\hline & & 7 & & AF-1.2_7_II \\
\hline \multirow{4}{*}{2} & \multirow{4}{*}{ AF-2.1 } & 5 & \multirow{2}{*}{ CEM I } & AF-2.1_5_I \\
\hline & & 7 & & AF-2.1_7_I \\
\hline & & 5 & \multirow{2}{*}{ CEM II } & AF-2.1_5_II \\
\hline & & 7 & & AF-2.1_7_II \\
\hline
\end{tabular}




\begin{tabular}{|c|c|c|c|c|}
\hline & \multirow{4}{*}{ AF-2.2 } & 5 & \multirow{2}{*}{ CEM I } & AF-2.2_5_I \\
\hline & & 7 & & AF-2.2_7_I \\
\hline & & 5 & \multirow{2}{*}{ CEM II } & AF-2.2_5_II \\
\hline & & 7 & & AF-2.2_7_II \\
\hline \multirow{8}{*}{3} & \multirow{4}{*}{ AF-3.1 } & 9 & \multirow{2}{*}{ CEM I } & AF-3.1_9_I \\
\hline & & 11 & & AF-3.1_11_I \\
\hline & & 9 & CᄃM & AF-3.1_9_II \\
\hline & & 11 & CEIVI I & AF-3.1_11_II \\
\hline & \multirow{4}{*}{ AF-3.2 } & 9 & \multirow{2}{*}{ CEM I } & AF-3.2_9_I \\
\hline & & 11 & & AF-3.2_11_I \\
\hline & & 9 & \multirow{2}{*}{ CEM II } & AF-3.2_9_II \\
\hline & & 11 & & AF-3.2_11_II \\
\hline
\end{tabular}

\subsection{Spraying procedure}

All mixes were sprayed with a MEYCO Altera wet-mix machine (Figure 2.a), an oilhydraulically driven twin-piston pump that also incorporated a peristaltic dosing unit for accelerators and a $10 \mathrm{~m}^{3} / \mathrm{min}$ diesel air compressor. A simple device was designed to facilitate the handling of the nozzle fixed to the forks of a forklift truck for stability and consistency of spraying position and angle (Figure 2.b).

The mixes were sprayed outdoors. The parameters of the spraying process were fixed with a pumped concrete flow of $4.4 \mathrm{~m}^{3} / \mathrm{h}$ (equivalent to 20 strokes per minute), an air pressure of 4 bars, and an accelerator-dosing flow between 4.0 and $4.5 \mathrm{l} / \mathrm{min}$.

The material was sprayed on to metallic test panels (500x500x150 mm), at an angle of $20^{\circ}$ from the vertical according to UNE-EN 14487-2:2008 (European Committee for Standarization, 2008). The distance between the nozzle and the test panels was constant and equal to $1.5 \mathrm{~m}$ (Figure 2.b). Like in most real case applications, no curing was performed on the spraying moulds in order to avoid interfering with the test up to $24 \mathrm{~h}$. 

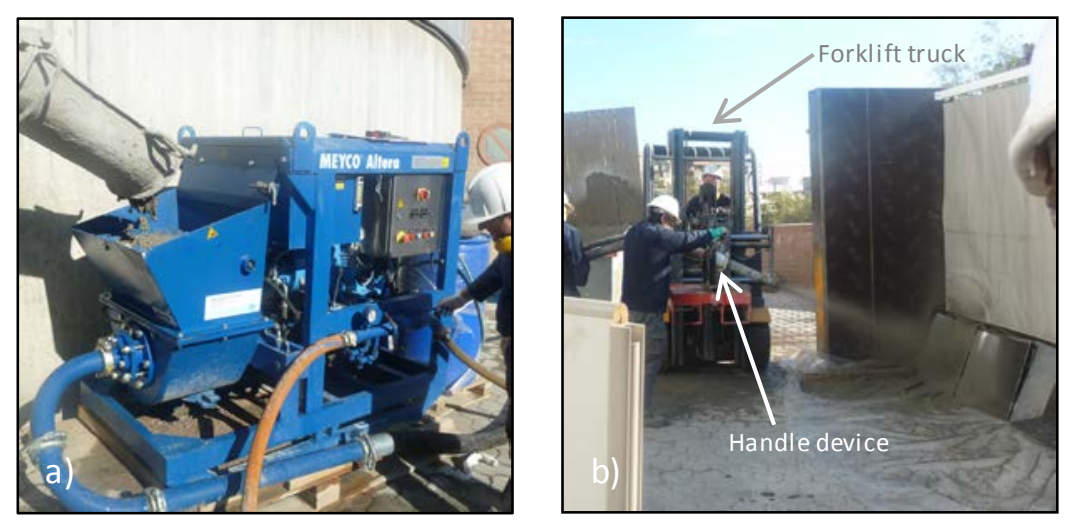

Figure 2- Wet-mix spraying machine a) and test panel position b)

\subsection{Testing methods}

According to the European standard UNE-EN 14488-2:2006 (European Committee for Standarization, 2007), two methods are available to evaluate the development of the compressive strength of sprayed concrete at early ages. The penetration needle test (Figure 3.a) is used to estimate the compressive strength from 3 to $30 \mathrm{~min}$, whereas the stud driving method (Figure 3.b) is applicable to estimate the strength from 2 to $24 \mathrm{~h}$.
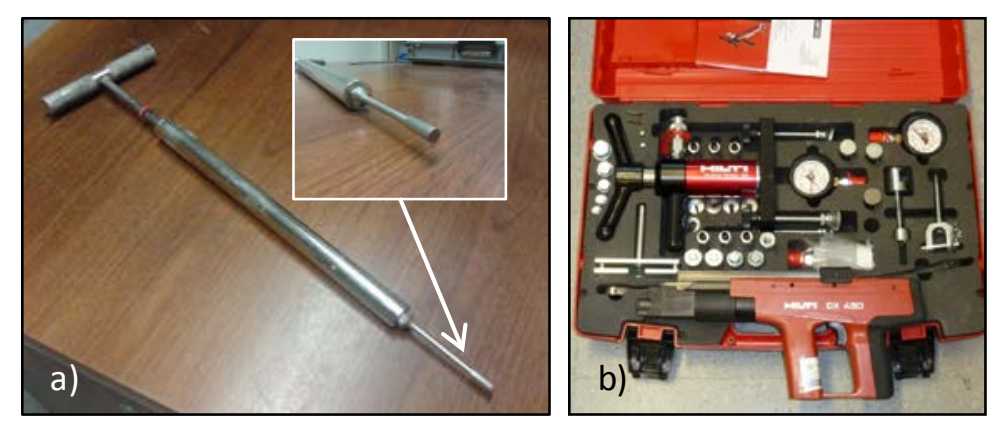

Figure 3- Penetration needle test a) and stud driving method $b$ )

Both methods are indirect and therefore several values are required to evaluate the compressive strength. In accordance with UNE-EN 14488-2:2007 (UNE-EN 14488-2:2006, 2007) an average of 10 measurements were taken at each age. The penetration needle test was performed at 3, 6, 10, 20 and $30 \mathrm{~min}$, and the stud driving method at 2, 4, 6, 12 and $24 \mathrm{~h}$.

Moreover, the evolution of temperature was recorded for each mix using a data logger and type $\mathrm{k}$ thermocouples (Figure 4.a), taped to the test panels (Figure 4.b). The temperature was measured every minute up to $24 \mathrm{~h}$. Another thermocouple recorded the ambient temperature. 

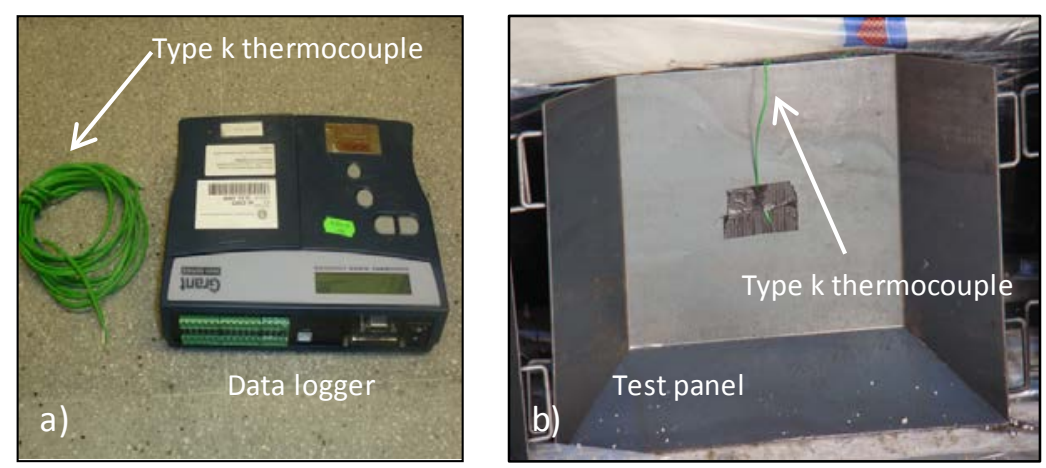

Figure 4-Data logger and thermocouples a) and assembly of thermocouples in the test panel b)

In addition, the mix AF-3.1_9_I was sprayed in a mould with two thermocouples arranged at different positions (Figure 5) in order to consider the effect of the thickness of the sprayed layer on the evolution of temperature results and to calibrate the FEM. In that sense, the first thermocouple was centred on the mould at $150 \mathrm{~mm}$ from the top in a low position (TC_L), whereas the second (TC_H) was set at the same position but at a height of $75 \mathrm{~mm}$. This height was achieved using a piece of wood since this material has a very low thermal conductivity.

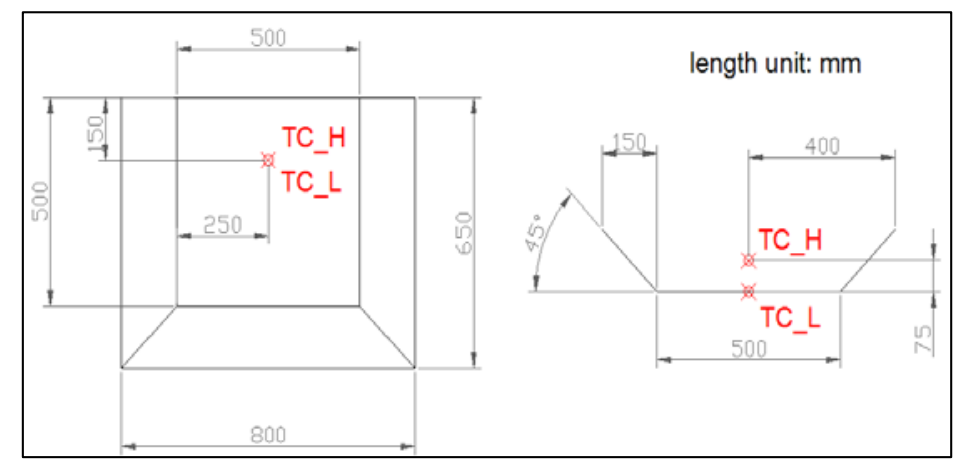

Figure 5-Arrangement of the thermocouples in the mould

\subsection{Modelling}

Besides the experimental tests, a thermal analysis was performed using a FEM. The aim of the analysis is to generalize the maturity curves obtained experimentally under laboratory conditions to the situations found in reality. For that, two models were analysed. The first of them (Model 1) reproduces the test performed with the panels in laboratory condition. Through an iterative procedure considering the experimental results, it is used to derive the curve of heat release due to the chemical reactions experienced by the material. This curve serves as an input parameter for Model 2, which simulates the conditions found in the real structure and allows 
estimating the evolution of temperature expected in reality. As a result, a simplified correlation may be derived between the maturity index measured in laboratory and in the real structure. The same analysis may be repeated for several structural types and surrounding conditions, deriving specific correlations for each case.

In both models, the software ANSYS 9.0 was used, as it can model the thermal behaviour of construction materials under established boundary conditions. In this sense, ANSYS applies the Fick's law of diffusion to evaluate the heat transfer (Eq. 3). This equation relates the evolution of temperature $(T)$ in time $(t)$ with the temperature in a determined location $(x)$ multiplied for the diffusivity of the material $(D)$. This parameter depends on the conductivity $(K)$, the specific heat (c) and the density $(\rho)$ of the material studied.

$$
\frac{\partial T}{\partial t}=D \cdot \frac{\partial^{2} T}{\partial x^{2}}=\left(\frac{K}{c \cdot \rho}\right) \cdot \frac{\partial^{2} T}{\partial x^{2}}
$$

\section{Model 1 - Test simulation}

A 2D model of the central section of the mould sprayed during the experimental program was considered. The geometry of the model was inputted into ANSYS, as presented in Figure 6.a. The thermal characteristics of the sprayed concrete and the steel were inputted, including the conductivity $(K)$, the specific heat $(c)$ and the density $(\rho)$ (Table 5). ASNYS then meshed the geometry using triangular elements, as shown in Figure 6.b. It is important to remark that the models were analysed with different mesh refinements to mitigate the possible influence of this parameter in the results. 


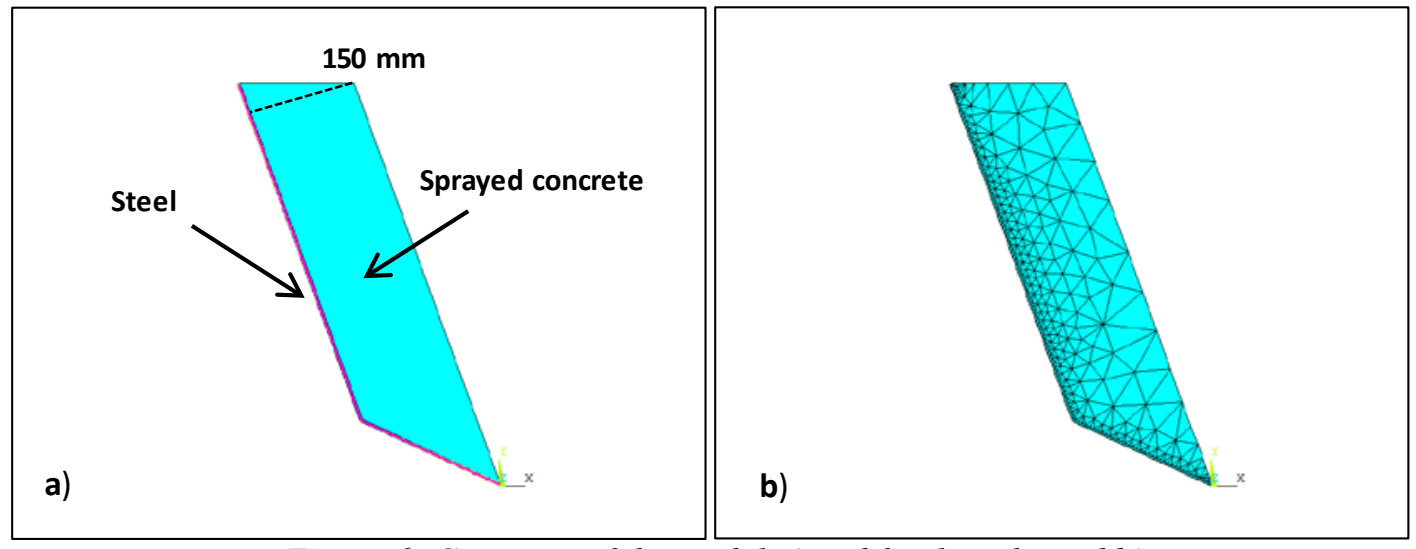

Figure 6- Geometry of the model a) and final mesh used b)

The initial temperature of materials and of the evolution of temperatures of the environment were defined according with the measurements performed in each test of the experimental program. A convective boundary condition was established between the concrete and the ambient and between the steel and the environment, assuming film coefficients respectively of 0.10 and $19.00 \mathrm{~kJ} /(\mathrm{h} \cdot \mathrm{m} \cdot \mathrm{K})$. Other material features such as the specific heat (c) the thermal conductivity (k) and the density $(\rho)$ are presented in Table 5.

Table 5- Material features

\begin{tabular}{|c|c|c|c|c|}
\hline \multicolumn{2}{|c|}{ Material } & $\mathbf{K}(\mathbf{k J} /(\mathbf{h} \cdot \mathbf{m} \cdot \mathbf{K}))$ & $\mathbf{c ~ ( k J / ( k g \cdot K ) )}$ & $\mathbf{\rho ~}\left(\mathbf{k g} / \mathbf{m}^{\mathbf{3}}\right)$ \\
\hline \multicolumn{2}{|c|}{ Steel } & 154 & 0.49 & 7600 \\
\hline \multicolumn{2}{|c|}{ Sprayed concrete } & 6.12 & 0.75 & 2000 \\
\hline \multirow{3}{*}{ Ground } & Clay & 5.40 & 0.92 & 800 \\
\cline { 2 - 5 } & Limestone & 4.68 & 0.91 & 2300 \\
\cline { 2 - 5 } & Stone & 18.00 & 0.84 & 2600 \\
\hline
\end{tabular}

The calibration of the model was performed with the mix AF-3.1_9_I, which had thermocouples installed in different positions. The energy released over time due to the chemical reactions was calibrated manually so that the evolution of temperature of the sprayed layer fits the measurements from the experimental results.

\section{Model 2 - Real structure simulation}

After calibrating Model 1, a new geometry was used (Figure 7) to consider the construction design parameters such as type of ground support and thickness of the sprayed concrete layers. 
Since one of the most common application of the material occurs in underground structures, the sprayed concrete was simulated in a tunnel.

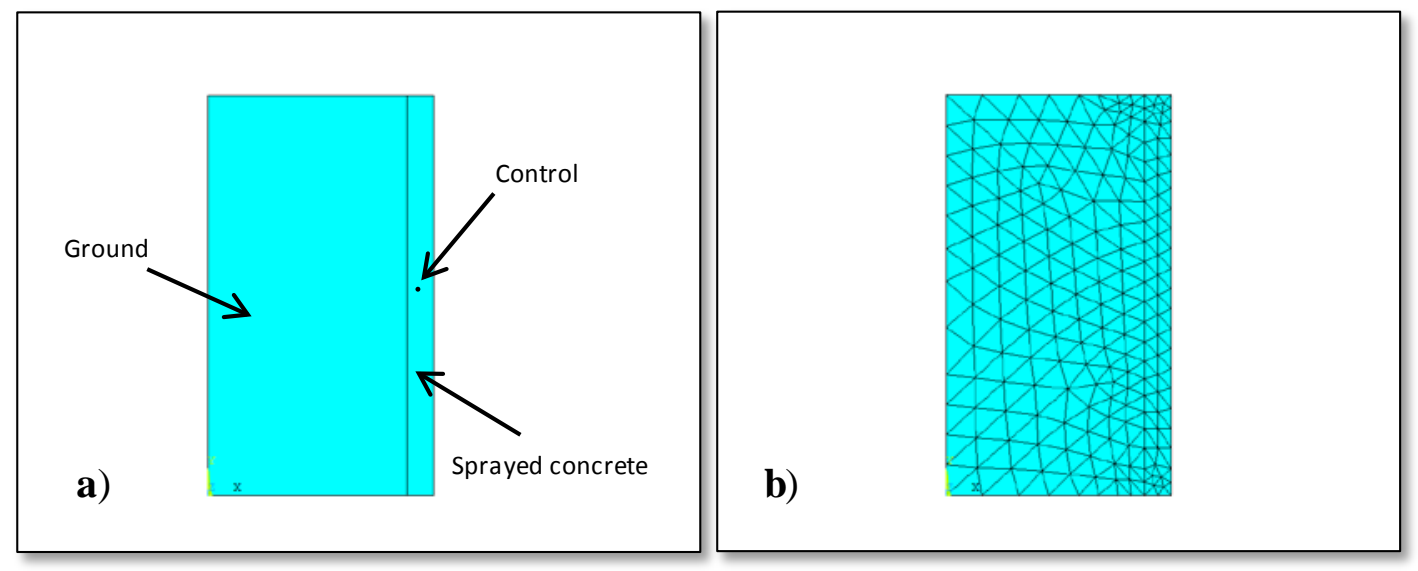

Figure 7- Geometry of the model of the lining of a tunnel a) and mesh generated $b$ )

In this sense, given that the ambient temperature inside the tunnel is relatively constant over time, the inside temperature was considered $18{ }^{\circ} \mathrm{C}$ throughout the analysis. Three types of ground support were considered: saturated clay (clay), limestone, and hard stone. The thermal properties of these three materials are shown in Table 5. Finally, three different thicknesses of sprayed concrete were used in each analysis: 100, 150 and $200 \mathrm{~mm}$. To avoid the effect of temperature variations over the surface, the control point is always considered in the centre of the layer, as depicted in Figure 7.a.

\section{Results and analysis}

This section presents the results of this study, starting with an analysis of the experimental results in the laboratory. The experimental relationship between the compressive strength and the evolution of temperature is then discussed. Finally, the results obtained from running the finite element models are presented in order to adapt the experimental results to the construction conditions.

To simplify the interpretation of the tendencies, only the results of mixes produced with accelerators AF-1.1, AF-2.1 and AF-3.1 are presented since other mixes from the same family follow a similar trend. 


\subsection{Experimental results}

\subsubsection{Evolution of Temperature}

The evolutions of temperature for the mixes are presented in Figure 8. The curves reveal an initial increase of temperature due to the early reaction between the cement and the accelerators. After that, either a slight decrease of temperature or a reduction of the increase rate is observed, thus characterizing a dormant period. Next, a second greater peak of temperature due to the hydration of silicates $\left(\mathrm{C}_{2} \mathrm{~S}\right.$ and $\left.\mathrm{C}_{3} \mathrm{~S}\right)$ is verified in most of the curves. Finally, the material tends to reach equilibrium with the environmental temperature. These observations are consistent with former studies performed by Neville, Julliand and Galobardes (Neville, 2008; Juliand, 2009; Galobardes, 2013).

The only exceptions observed were in the case of mixes of cement CEM I with a low or high dose of AF-1.1. This is possibly due to the presence of phosphoric acid in the accelerator formulation, as observed in other studies (Julliand, 2009). On the contrary, AF-1.1 shows good affinity with CEM II, which may be related with the clinker fineness and the content of limestone filler present.
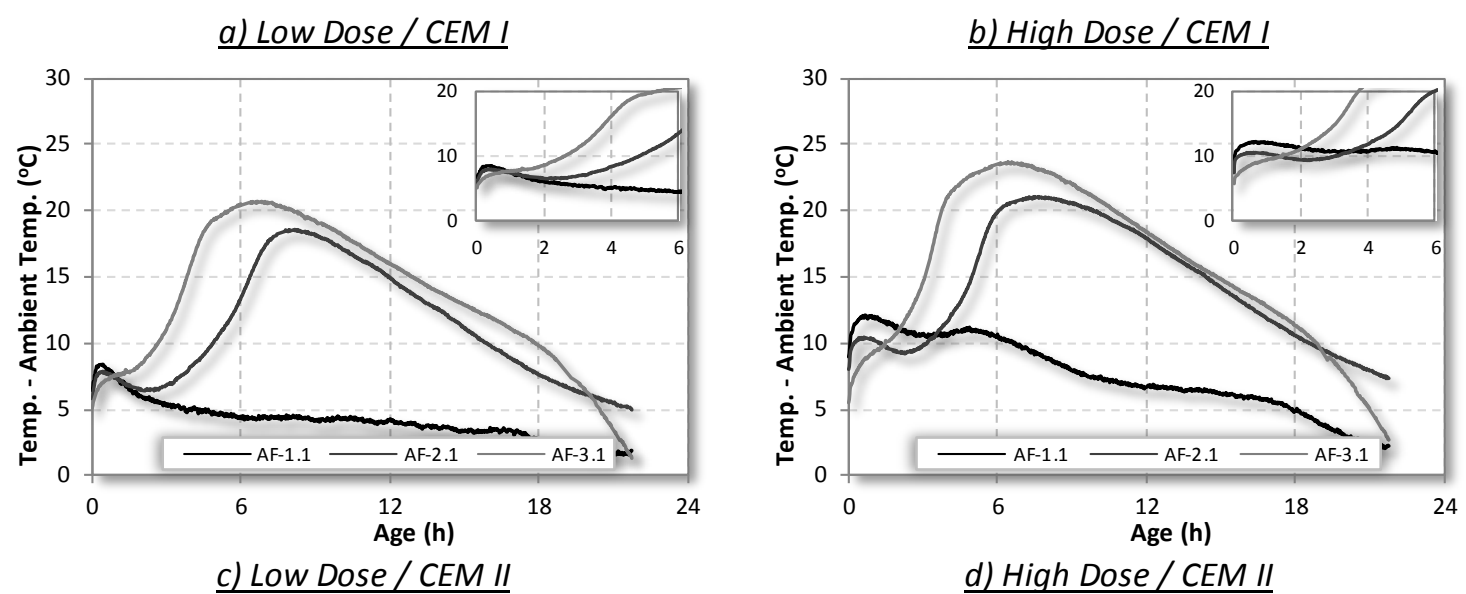

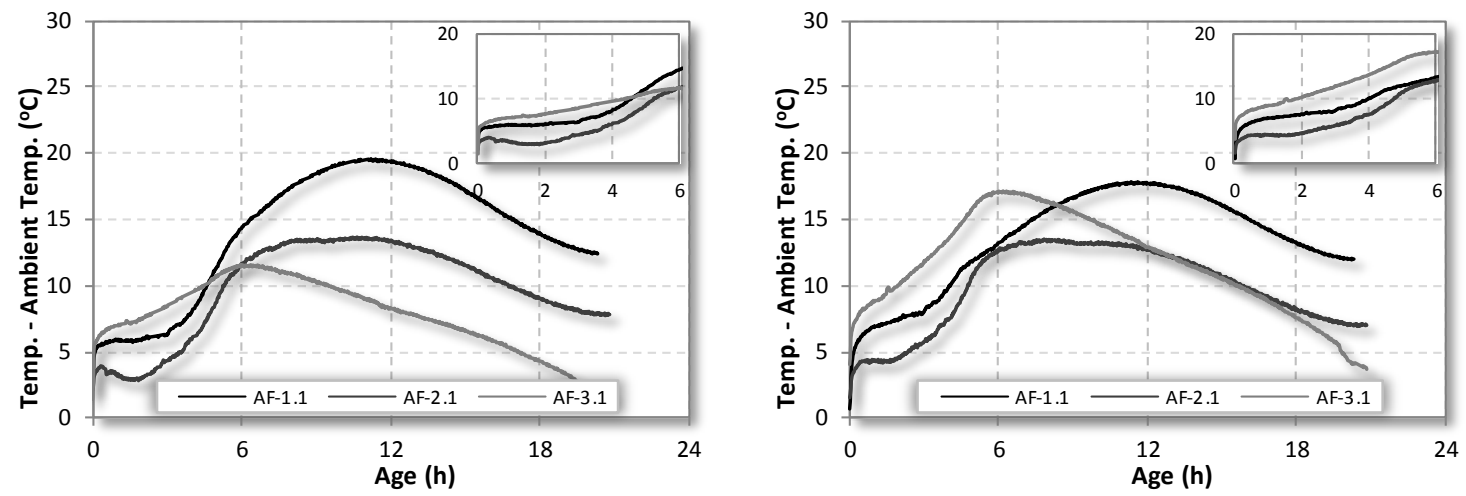

Figure 8-Evolution of temperature over $24 \mathrm{~h}$ considering type of cement and dose of accelerator

Table 6 presents characteristic points extracted from the curves in Figure 8. These points are represented in terms of the value $\left(T_{\max }\right)$ and the time $\left(t_{T \max }\right)$ of the maximum temperature, first increasing of temperature $\left(T_{1 P}\right)$, the second temperature peak $\left(T_{2 P}\right)$ and the minimum temperature between peaks $\left(T_{\text {Min1P-2P }}\right)$. Notice that this last value is related to the dormant period. The table also presents the energy released during the hydration (Et_), which was calculated as the integral of the evolution in time, for each characteristic point $\left(h \cdot{ }^{\circ} \mathrm{C}\right)$.

Table 6- Evolution of temperature characteristic points

\begin{tabular}{|c|c|c|c|c|c|c|}
\hline \multicolumn{7}{|c|}{ Low Dose } \\
\hline & AF-1.1_5_I & AF-2.1_5_I & AF-3.1_9_I & AF-1.1_5_II & AF-2.1_5_II & AF-3.1_9_II \\
\hline $\mathrm{T}_{\max }\left({ }^{\circ} \mathrm{C}\right)$ & 8.37 & 18.56 & 20.68 & 19.59 & 13.67 & 11.61 \\
\hline $\mathbf{t} \_\mathbf{T}_{\max }$ (h:min:s) & 0:26:00 & 8:09:00 & 6:39:00 & $11: 11: 00$ & $10: 27: 00$ & $5: 55: 00$ \\
\hline Et_T $T_{\text {max }}\left(h \cdot{ }^{\circ} \mathrm{C}\right)$ & 215.06 & 5156.38 & 6607.35 & 8397.89 & 5499.68 & 3081.91 \\
\hline $\mathrm{T}_{1 \mathrm{P}}\left({ }^{\circ} \mathrm{C}\right)$ & 8.37 & 7.84 & 7.97 & 5.97 & 3.95 & 7.37 \\
\hline$t_{-} T_{1 P}$ (h:min:s) & 0:26:00 & 0:25:00 & 1:21:00 & 0:54:00 & 0:18:00 & 1:21:00 \\
\hline Et_T $T_{1 P}\left(h \cdot{ }^{\circ} \mathrm{C}\right)$ & 215.06 & 191.31 & 583.50 & 305.56 & 67.63 & 544.51 \\
\hline $\mathrm{T}_{2 \mathrm{P}}\left({ }^{\circ} \mathrm{C}\right)$ & - & 18.56 & 20.68 & 19.59 & 13.67 & 11.61 \\
\hline$t \_T_{2 P}$ (h:min:s) & - & 8:09:00 & 6:39:00 & $11: 11: 00$ & $10: 27: 00$ & 5:55:00 \\
\hline Et_T $T_{2 P}\left(h \cdot{ }^{\circ} \mathrm{C}\right)$ & - & 5156.38 & 5381.44 & 8397.89 & 5499.68 & 3081.91 \\
\hline$T_{\min 1 \mathrm{P}-2 \mathrm{P}}\left({ }^{\circ} \mathrm{C}\right)$ & - & 6.37 & 7.74 & 5.72 & 2.83 & 7.11 \\
\hline$t_{-} T_{\min 1 \mathrm{P}-2 \mathrm{P}}(\mathrm{h}: \min : \mathrm{s})$ & - & 2:29:00 & 1:30:00 & 1:35:00 & 1:48:00 & 1:29:00 \\
\hline$E t_{-} T_{\min 1 \mathrm{P}-2 \mathrm{P}}\left(h \cdot{ }^{\circ} \mathrm{C}\right)$ & - & 1048.40 & 653.78 & 545.48 & 358.62 & 602.23 \\
\hline \multicolumn{7}{|c|}{ High Dose } \\
\hline & AF-1.1_7_I & AF-2.1_7_I & AF-3.1_11_I & AF-1.1_7_II & AF-2.1_7_II & AF-3.1_11_II \\
\hline $\mathrm{T}_{\max }\left(l^{\circ} \mathrm{C}\right)$ & 12.08 & 21.04 & 23.66 & 17.85 & 13.53 & 17.16 \\
\hline $\mathbf{t}_{-} \mathbf{T}_{\max }(\mathrm{h}: \min : \mathrm{s})$ & 0:39:00 & 7:38:00 & $6: 24: 00$ & 11:19:00 & 7:48:00 & 6:09:00 \\
\hline Et_- $T_{\text {max }}\left(h \cdot{ }^{\circ} \mathrm{C}\right)$ & 458.63 & 6324.95 & 5072.27 & 8378.88 & 3920.94 & 4535.76 \\
\hline $\mathrm{T}_{1 \mathrm{P}}\left({ }^{\circ} \mathrm{C}\right)$ & 12.08 & 10.42 & 10.16 & 7.22 & 4.44 & 9.80 \\
\hline$t_{-} T_{1 P}$ (h:min:s) & 0:39:00 & 0:35:00 & 1:28:00 & 1:30:00 & 1:07:00 & 1:29:00 \\
\hline Et_T $T_{1 P}\left(h \cdot{ }^{\circ} \mathrm{C}\right)$ & 458.63 & 360.54 & 774.99 & 577.83 & 276.71 & 752.49 \\
\hline $\mathrm{T}_{2 \mathrm{P}}\left({ }^{\circ} \mathrm{C}\right)$ & 11.02 & 21.04 & 23.66 & 17.85 & 13.53 & 17.16 \\
\hline$t_{-} T_{2 P}$ (h:min:s) & 5:05:00 & 7:38:00 & $6: 24: 00$ & 11:19:00 & 7:48:00 & 6:09:00 \\
\hline
\end{tabular}




\begin{tabular}{|c|c|c|c|c|c|c|}
\hline $\mathrm{Et}_{-} \mathrm{T}_{2 \mathrm{P}}\left(\mathrm{h} \cdot{ }^{\circ} \mathrm{C}\right)$ & 3385.17 & 6324.95 & 6253.88 & 8378.88 & 3920.94 & 4535.76 \\
\hline$T_{\min 1 \mathrm{P}-2 \mathrm{P}}\left({ }^{\circ} \mathrm{C}\right)$ & 10.41 & 9.17 & - & 7.22 & 4.18 & 9.59 \\
\hline $\mathrm{t}_{1} \mathbf{T}_{\min 1 \mathrm{P}-2 \mathrm{P}}(\mathrm{h}: \min : \mathrm{s})$ & $3: 07: 00$ & $2: 16: 00$ & - & $1: 30: 00$ & $1: 19: 00$ & $1: 35: 00$ \\
\hline Et_- $T_{\min 1 \mathrm{P}-2 \mathrm{P}}\left(\mathrm{h} \cdot{ }^{\circ} \mathrm{C}\right)$ & 2115.96 & 1345.94 & - & 577.83 & 327.84 & 811.15 \\
\hline
\end{tabular}

Regarding the first increase of temperature $\left(T_{1 P}\right)$, mixes with accelerator AF-1.1 present the highest temperature in the mixes with cement CEM I. In contrast, mixes with cement CEM II present the highest temperature with the accelerator AF-3.1, independently of the dose of accelerator. This increase of temperature becomes more pronounce as the dose of accelerator increases. Such outcome is the result of a higher content of accelerators that are available to react with the cement. Furthermore, the mixes with cement CEM I have higher temperatures than those with cement CEM II. This is due to the higher amount of clinker, and therefore aluminates $\left(\mathrm{C}_{3} \mathrm{~A}\right)$ of cement CEM I in comparison with cement CEM II. The only exception is observed in mixes with AF-1.1, which shows greater affinity with cement CEM II.

Regarding the $2^{\text {nd }}$ peak of temperature $\left(T_{2 P}\right)$, in case of mixes with cement CEM I the highest values are measured for the accelerator AF-3.1 whereas mixes with cement CEM II present the highest temperature with the accelerator AF-1.1. Furthermore, the results show that when increasing the dose of accelerator the peaks of temperature are around $25 \%$ higher with mixes with cement CEM I, regardless of the accelerator used. In general, the $2^{\text {nd }}$ peak of temperature $\left(T_{2 P}\right)$ is higher for mixes with cement CEM I than those with cement CEM II, probably due to the larger clinker content of the former. Again, the only exception is observed in mixes with AF-1.1.

It is noteworthy that mixes with $\mathrm{AF}-3.1$ present the $2^{\text {nd }}$ peak before the mixes with other accelerators for all cement types and doses analysed. This indicates that the chemical formulation of AF-3.1 possibly is more active in terms of accelerating the hydration of silicates $\left(\mathrm{C}_{2} \mathrm{~S}\right.$ and $\left.\mathrm{C}_{3} \mathrm{~S}\right)$ in comparison with other admixtures studied.

The findings also reveal that mixes that present higher temperatures in the first peak tend to show lower temperatures in the second peak. This may be explained by the phase of cement that 
reacts with the accelerators. For example, if the accelerator reacts mainly with the aluminates, a higher $1^{\text {st }}$ peak of temperature should be observed. In contrast, if the accelerators are more active on the silicates of the cement, a higher $2^{\text {nd }}$ peak should be observed. Another explanation could be that less active mixes present smaller $1^{\text {st }}$ peaks, leaving more aluminates to react over time and to contribute to the temperature increase of the $2^{\text {nd }}$ peak.

The dormant period is longer for the low doses of accelerators for both cement types. In this sense, mixes with AF-2.1 present the longest dormant periods $\left(T_{\text {Min1P-2P }}\right)$. This period is not as long in mixes with accelerator AF-3.1 since a decrease of temperature is not observed. Furthermore, an increase in the dose of accelerator produces shorter dormant.

Figure 9 presents the evolutions of temperature obtained recording the mix produced with AF3.1_9_I taking into account the different thermocouple positions shown in Figure 5. Notice that the tendency shown for both evolutions of temperature is the same and equal to the ones presented above.

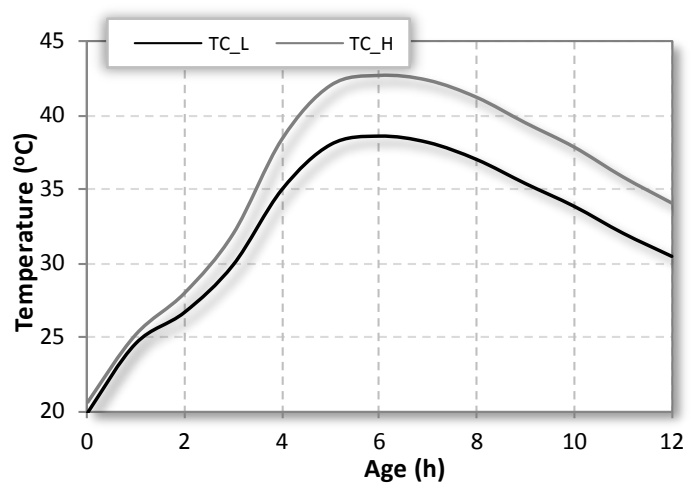

Figure 9- Evolution of temperature considering thermocouple position

The evolutions of temperature obtained are similar in shape since they present an initial increase of temperature, a slightly slower dormant period, a second steep increase of temperature and a decrease of temperature after the maximum. The temperatures gathered for TC_H are higher than the ones obtained for TC_L due to their position and the consequent heat transfer (Figure 5). TC_H was in the middle of the sprayed concrete and therefore the heat generated was higher than for TC_L. 


\subsubsection{Penetration needle test}

The results for the compressive strength (and their variance) obtained with the penetration needle test are presented in Table 7. Regarding the type of cement, the results obtained are similar for the mixes with cements CEM I and CEM II. This demonstrates the lower importance of the type of cement up to $30 \mathrm{~min}$. Therefore, the type of accelerator is the parameter that most influences the strength measured in the early ages. In general, an increase in dose leads to higher strength. This is reasonable as more accelerator is available to react with the cement. In this sense, higher results are achieved with AF-2.1 and with AF-3.1 for the cements CEM I and CEM II, respectively. The main exception is observed for mixes with AF-1.1, which, regardless of the cement type, present the highest compressive strength for the low dose.

Table 7- Compressive strength (MPa) and variance (\%) obtained by the penetration needle test

\begin{tabular}{|c|c|c|c|c|c|c|}
\hline \multicolumn{7}{|c|}{ Low Dose } \\
\hline Age (min) & AF-1.1_5_I & AF-2.1_5_I & AF-3.1_9_I & AF-1.1_5_II & AF-2.1_5_II & AF-3.1_9_II \\
\hline \multirow{2}{*}{3} & 0.39 & 0.00 & 0.19 & 0.59 & 0.30 & 0.50 \\
\hline & (22.30) & (12.74) & (21.48) & (15.61) & (17.34) & (19.20) \\
\hline \multirow{2}{*}{6} & 0.45 & 0.37 & 0.37 & 0.78 & 0.36 & 0.67 \\
\hline & (48.14) & (23.60) & (10.16) & (11.90) & (26.21) & (16.66) \\
\hline \multirow{2}{*}{10} & 0.56 & 0.42 & 0.51 & 1.01 & 0.43 & 0.73 \\
\hline & (23.48) & (27.38) & (9.84) & (5.45) & (15.27) & (30.26) \\
\hline \multirow{2}{*}{15} & 0.67 & 0.49 & 0.56 & - & 0.56 & 1.03 \\
\hline & (20.94) & (19.57) & (15.49) & - & (18.67) & (21.54) \\
\hline \multirow{2}{*}{20} & 0.78 & 0.57 & 0.61 & - & 0.69 & 1.24 \\
\hline & (18.39) & (11.75) & (7.78) & - & (22.06) & (6.01) \\
\hline \multirow{2}{*}{30} & 0.98 & 0.87 & 0.84 & - & 0.86 & - \\
\hline & (13.56) & (9.44) & (6.39) & - & (8.40) & - \\
\hline \multicolumn{7}{|c|}{ High Dose } \\
\hline Age (min) & AF-1.1_7_I & AF-2.1_7_I & AF-3.1_11_I & AF-1.1_7_II & AF-2.1_7_II & AF-3.1_11_II \\
\hline \multirow{2}{*}{3} & 0.41 & 0.44 & 0.36 & 0.44 & 0.43 & 0.80 \\
\hline & (19.81) & (15.09) & (63.62) & (19.47) & (34.32) & (9.70) \\
\hline \multirow{2}{*}{6} & 0.49 & 0.72 & 0.40 & 0.71 & 0.52 & 0.98 \\
\hline & (21.3\%) & (10.07) & (7.31) & (25.15) & (25.68) & (9.21) \\
\hline \multirow{2}{*}{10} & 0.55 & 0.98 & 0.48 & 0.98 & 0.58 & 1.02 \\
\hline & (29.72) & (9.77) & (12.38) & (28.66) & (25.93) & (5.75) \\
\hline \multirow{2}{*}{15} & 0.79 & - & 0.80 & - & 0.78 & - \\
\hline & (20.89) & - & (13.48) & - & (15.69) & - \\
\hline \multirow{2}{*}{20} & 1.04 & - & 0.91 & - & 0.99 & - \\
\hline & (12.07) & - & (10.88) & - & (5.44) & - \\
\hline \multirow[t]{2}{*}{30} & - & - & - & - & - & - \\
\hline & - & - & - & - & - & - \\
\hline
\end{tabular}


The penetration test has a range of application between $0 \mathrm{MPa}$ and approximately $1.3 \mathrm{MPa}$. It was observed that for mixes with a low dose of accelerator, values are recorded up to 30 minutes in almost all mixes, and show a slow gain of compressive strength over time. Conversely, mixes with the high dose could only be tested up to 10 or 20 minutes, due to the limit of the testing equipment. In that sense, results stop around 1.0 MPa because the next estimations could not be taken due to the rapid gain of strength. It is important to highlight the fast gain of strength in mixes with the low dose of AF-1.1 and cement CEM II, which at 10 min showed the same strength of mixes with other accelerators at 30 minutes. This is probably due to the higher affinity of AF-1.1 with the cement CEM II, even for low doses. This phenomenon was also observed in the evolution of temperature over time.

Figure 10 illustrates the compressive strength results presented by the mixes considered in this section and the data for the early strength classes for young sprayed concrete: J1, J2 and J3 (European Committee for Standarization, 2008, Austrian Society for Construction Technology, 1992).

a) Low Dose / CEM I

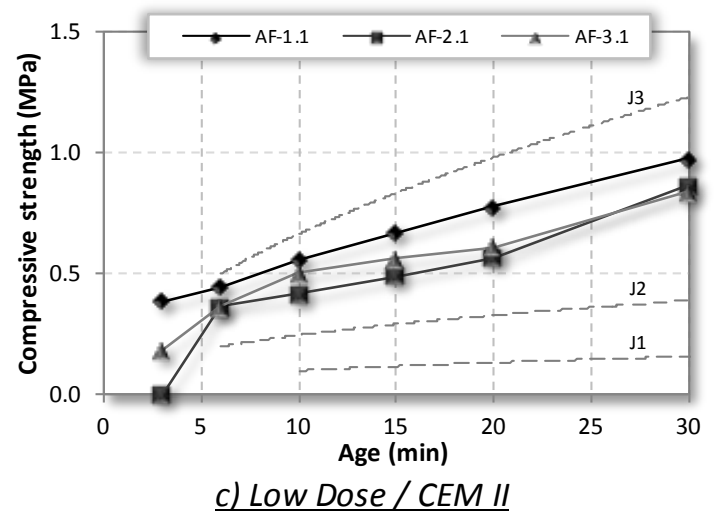

b) High dose / CEM I

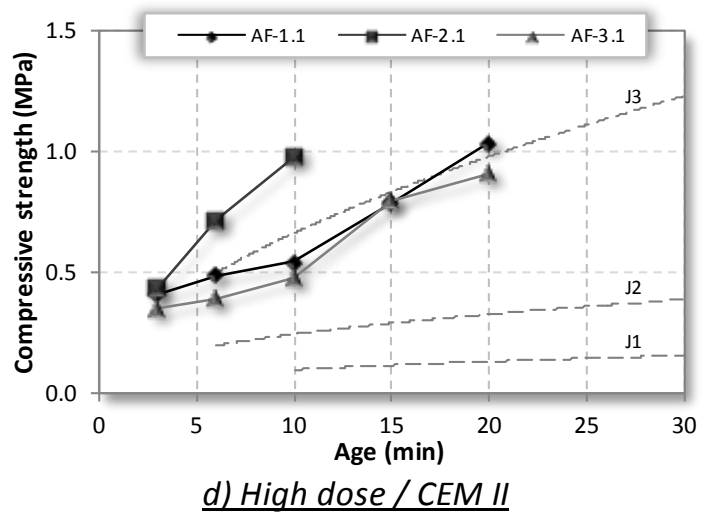



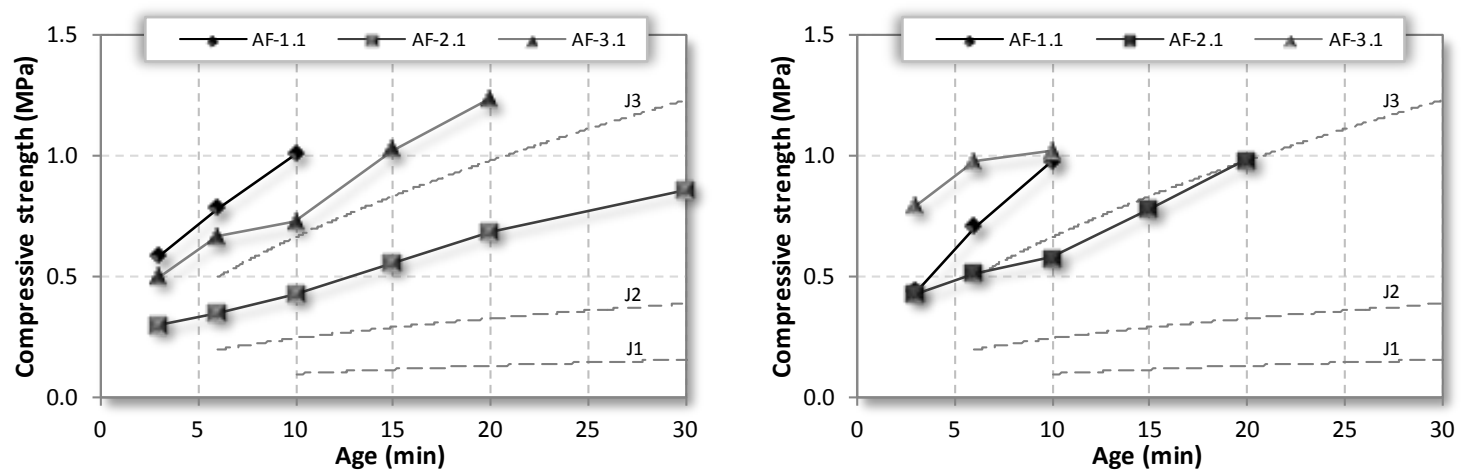

Figure 10-Compressive strength results considering type of cement and dose of accelerator

The results show that the strength development is classified as J2 or J3. Regarding the type of cement, mixes with CEM II relate more to curve J3 than the samples with CEM I. This is possibly due to the limestone filler in the cement CEM II, which contributes to the nucleation of the hydrated phases increasing the compressive strength at very early ages. In this case the mixes with accelerators AF-1.1 and AF-3.1 relate to curve J3, whereas AF-2.1 relate to curve J2, independently of the type of dose. This shows the lower affinity between the accelerator AF2.1 and the cement CEM II, as observed from analysing the evolution of temperature. This tendency was observed in the evolution of temperatures and is probably due to the hydration of $\mathrm{C}_{3} \mathrm{~A}$. Conversely, mixes produced with cement CEM I and low dose of accelerator relate more to curve J2. An increase in the dose of accelerator produces a small growth in the strength of the mixes with accelerators AF-1.1 and AF-3.1, which are still classified as J2. A higher influence is observed in the mix with AF-2.1 that presents a significant increase of strength and is classified as J3.

\subsubsection{Stud driving method}

The results of compressive strength (and their variance) obtained by the stud driving method are presented in Table 8. Regarding the type of cement, the results obtained are similar for the mixes with cement CEM I and for CEM II, although cement CEM I are slightly higher. This is due to the higher strength class of the cement and its importance from age $4 \mathrm{~h}$ onwards. However, the type of accelerator is still more important during this period. 


\begin{tabular}{|c|c|c|c|c|c|c|}
\hline \multicolumn{7}{|c|}{ Low Dose } \\
\hline Age (h) & AF-1.1_7_I & AF-2.1_7_I & AF-3.1_11_I & AF-1.1_7_II & AF-2.1_7_II & AF-3.1_11_II \\
\hline \multirow{2}{*}{4} & - & - & 4.15 & 4.43 & 3.82 & 2.90 \\
\hline & - & - & (16.14) & (14.61) & (20.39) & (22.22) \\
\hline \multirow{2}{*}{6} & - & 8.59 & 12.11 & 5.89 & 8.59 & 7.23 \\
\hline & - & (17.55) & (10.01) & (26.90) & (19.22) & (16.97) \\
\hline \multirow{2}{*}{12} & 5.82 & 15.63 & 17.26 & 17.47 & 15.63 & 11.72 \\
\hline & (27.60) & (19.22) & (21.43) & (23.03) & (17.76) & (16.63) \\
\hline \multirow{2}{*}{24} & 25.39 & 19.97 & 17.53 & 17.13 & 19.97 & 15.68 \\
\hline & (11.11) & (16.39) & (15.04) & (24.68) & (35.13) & (22.95) \\
\hline \multicolumn{7}{|c|}{ High Dose } \\
\hline Age (h) & AF-1.1_7_I & AF-2.1_7_I & AF-3.1_11_I & AF-1.1_7_II & AF-2.1_7_II & AF-3.1_11_II \\
\hline \multirow{2}{*}{4} & - & - & 5.44 & 3.51 & 5.66 & - \\
\hline & - & - & (17.07) & (19.61) & (9.38) & - \\
\hline \multirow{2}{*}{6} & 3.24 & 13.16 & 11.26 & 6.75 & 8.66 & 5.13 \\
\hline & (9.94) & (10.42) & (11.95) & (13.33) & (12.43) & (12.95) \\
\hline \multirow{2}{*}{12} & 4.88 & 22.48 & 14.62 & 13.18 & 17.93 & 7.38 \\
\hline & (16.66) & (16.35) & (11.85) & (17.49) & (12.73) & (25.62) \\
\hline \multirow{2}{*}{24} & 20.07 & 20.16 & 17.34 & 16.94 & 17.52 & 15.44 \\
\hline & (7.62) & (22.42) & (30.97) & (28.18) & (19.64) & (13.61) \\
\hline
\end{tabular}

In the first 6 hours, the type of accelerator and the additions in the cement have more influence. In this sense, higher results are achieved with AF-2.1 regardless of the type of cement and dose of accelerator. This is possibly related to the quicker hydration of the $\mathrm{C}_{2} \mathrm{~S}$ and $\mathrm{C}_{3} \mathrm{~S}$ of mixes with AF-2.1, which produces C-S-H chains able to provide compressive strength. This phenomenon is observed in the second peak of temperature. In contrast, mixes with AF-1.1 and AF-3.1 produced lower results in mixes with cement CEM I and CEM II, respectively. This probably indicates a lower affinity between the accelerators and the type of cements.

The stud driving method has a range of application from around $3 \mathrm{MPa}$ upwards, therefore the age of $4 \mathrm{~h}$ was established as the initial time of assessment. As a result, mixes with cement CEM II present values from $4 \mathrm{~h}$, indicating a more rapid gain of strength. On the contrary, mixes with cement CEM I could only be tested from 6 h onwards in most cases.

Figure 11 reveals the results can be classed as young sprayed concrete J2 and J3 (European Committee for Standarization , 2008; Austrian Society for Construction Technology, 1992). 


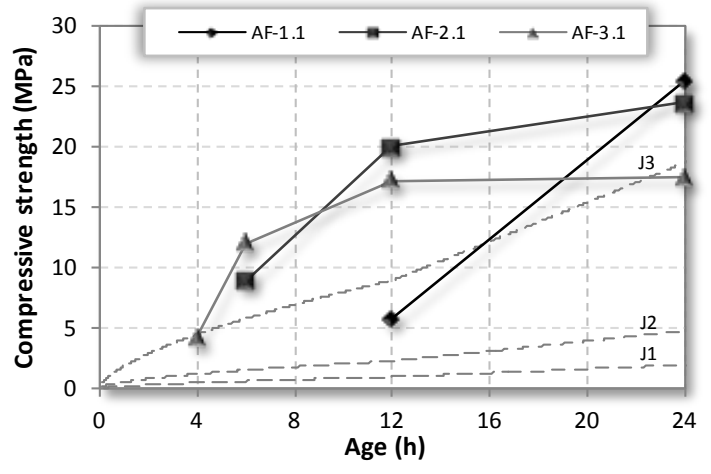

c) Low Dose / CEM II

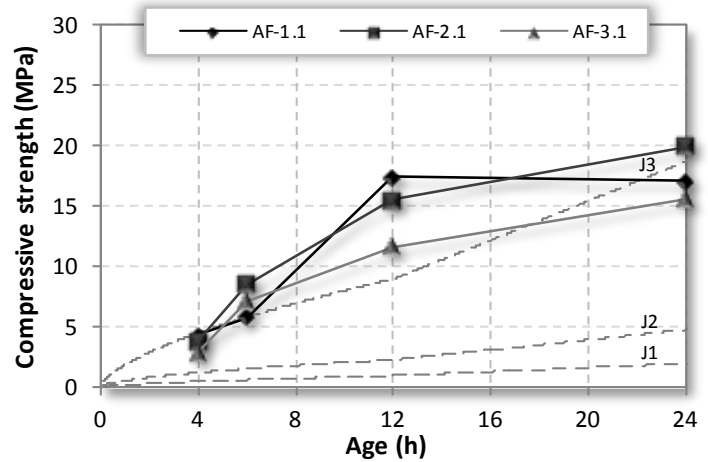

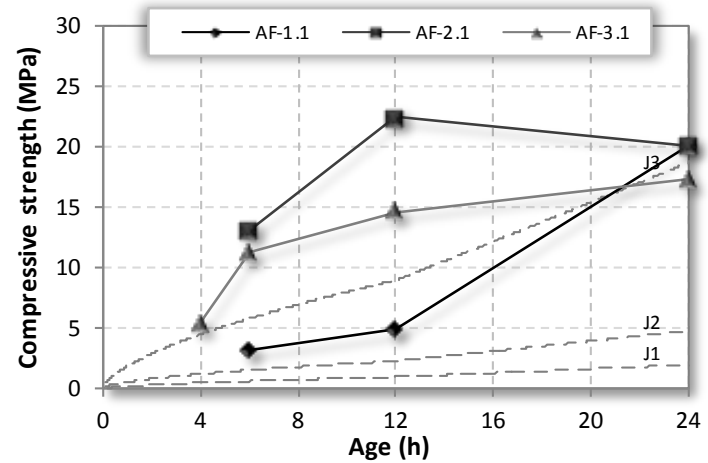

d) High dose / CEM II

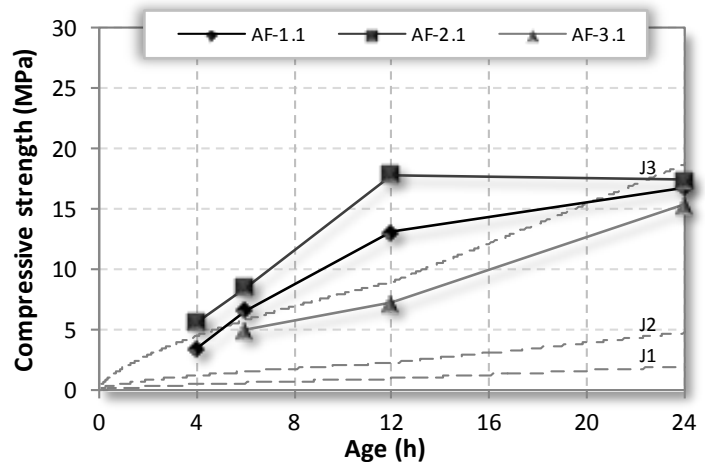

Figure 11-Compressive strength results considering type of cement and dose of accelerator

The mixes with cement CEM II present more closely curve J3, as commented before possibly due to the limestone filler. The only exception is the mix with a high dose of AF-3.1, classified as J2. Conversely, mixes with cement CEM I present the same behaviour regardless of the dose of accelerator. In this sense, mixes produced with AF-2.1 and AF-3.1 present more curve J3, whereas those with AF-1.1 are classified as J2. This difference is possibly due to the low affinity between accelerator AF-1.1 and cement CEM I, as observed in the evolution of temperature.

\subsection{Experimental relationship evolution of temperature and compressive strength}

The maturity indices obtained for each mix from the evolution of temperature are calculated according with Eq. 1. Figure 12 illustrates an example of this calculation for one of the mixes with AF-1.1. This calculation is repeated for the different ages of characterization of the compressive strength with the penetration needle and the study driving method. Consequently, several pair of values of maturity index (M) and the corresponding compressive strength (S) are obtained for each time. Notice that this assessment was made only with the results up to 12 
hours from spraying since this is the typical times for the advance of the construction is below this limit.
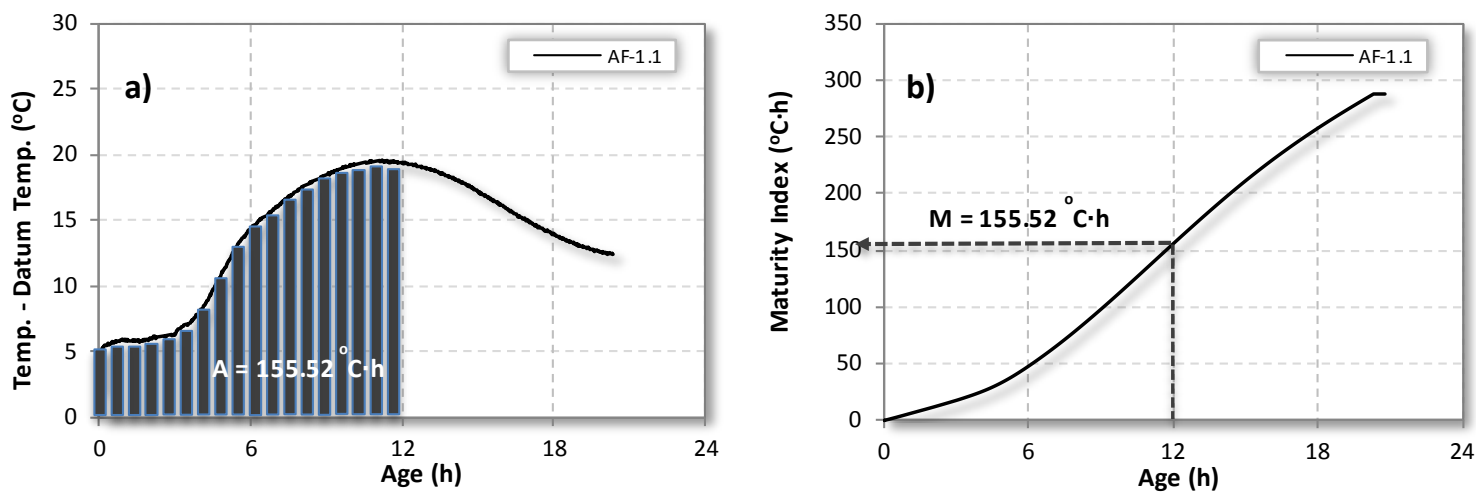

Figure 12-Relation between the evolution of temperature a) and the maturity index b), for mix AF-1.1

Curves were then fitted to the pair of values from each mix, using LAB Fit v.7.2.48. In a first approach, the fit was performed with the Plowman's equation that relate the values of $\mathrm{S}$ and $\mathrm{M}$ (Plowman, 1956). As a result, the parameter ' $a$ ' and ' $b$ ' that yield the best $\mathrm{R}^{2}$ were found. The same was repeated with the alternative equation proposed here (Eq. 3), which depends on the parameters $\mathrm{A}, \mathrm{B}$ and $\mathrm{C}$.

$$
S=A \cdot \operatorname{EXP}[B \cdot \operatorname{EXP}(C \cdot M)]
$$

Table 9 presents the $\mathrm{R}^{2}$ achieved with both equations. Notice that a poor fit was obtained with the Plowman's equation. In this case, values as low as 0.69 are observed, with an average of 0.81. It is evident that the Plowman's equation does not provide a good approximation of the correlation between the maturity index and the compressive strength due to the influence of the accelerator in the hydration kinetics of cement. Consequently it is not adequate for the application of the maturity method in such mixes. On the contrary, the alternative equation proposed here leads to a minimum $\mathrm{R}^{2}$ of 0.93 with an average of 0.99 . This suggests that Eq. 3 is more representative of sprayed concrete with accelerators.

Table 9- Parameters obtained by LAB Fit

\begin{tabular}{|c|c|c|c|c|c|c|c|}
\hline \multirow{2}{*}{ Accelerator } & \multirow{2}{*}{ Cement } & \multirow{2}{*}{ Dose } & \multicolumn{4}{|c|}{ Alternative proposal (Eq. 3) } & Plowman (Eq. 2) \\
\cline { 4 - 8 } & & & $\mathbf{A}$ & $\mathbf{B}$ & $\mathbf{C}$ & $\mathbf{R}^{\mathbf{2}}$ & $\mathbf{R}^{\mathbf{2}}$ \\
\hline \multirow{2}{*}{ AF-1.1 } & \multirow{2}{*}{ CEM I } & Low & 5.821 & -2.718 & -0.023 & 0.9998 & 0.8711 \\
\cline { 3 - 8 } & & High & 4.060 & -2.575 & -0.048 & 0.9255 & 0.9003 \\
\hline
\end{tabular}




\begin{tabular}{|l|c|c|c|c|c|c|c|}
\hline \multirow{3}{*}{ CEM II } & Low & 31.966 & -3.535 & -0.003 & 0.9958 & 0.6582 \\
\cline { 3 - 8 } & & High & 15.920 & -3.302 & -0.006 & 0.9978 & 0.7466 \\
\hline \multirow{4}{*}{ AF-2.1 } & \multirow{3}{*}{ CEM I } & Low & 23.724 & -4.115 & -0.006 & 1.0000 & 0.8003 \\
\cline { 3 - 8 } & & High & 24.160 & -3.616 & -0.007 & 1.0000 & 0.9277 \\
\cline { 3 - 8 } & \multirow{2}{*}{ CEM II } & Low & 17.292 & -3.954 & -0.008 & 0.9970 & 0.7516 \\
\cline { 3 - 8 } & & High & 21.085 & -3.430 & -0.006 & 0.9980 & 0.7844 \\
\hline \multirow{3}{*}{ AF-3.1 } & \multirow{2}{*}{ CEM I } & Low & 17.367 & -12.739 & -0.014 & 0.9988 & 0.7707 \\
\cline { 3 - 8 } & & High & 15.204 & -3.864 & -0.009 & 0.9944 & 0.8615 \\
\cline { 3 - 8 } & \multirow{2}{*}{ CEM II } & Low & 14.536 & -3.050 & -0.006 & 0.9825 & 0.7462 \\
\cline { 3 - 8 } & & High & 7.982 & -2.196 & -0.006 & 0.9995 & 0.9532 \\
\hline
\end{tabular}

Figure 13 presents the experimental results and the maturity curves obtained with Eq. 3 . The maturity curves are clearly influenced by the parameters studied, namely type of cement and type/dosage of accelerator. Considering the type of cement, all the mixes present similar tendencies. Regarding the dose of accelerator, the results of mixes with accelerator AF-1.1 and AF-3.1 show that an increase of the dose entails higher values of maturity index to achieve the same compressive strength. This is not observed for mixes produced with AF-2.1.

a) Low Dose / CEM I

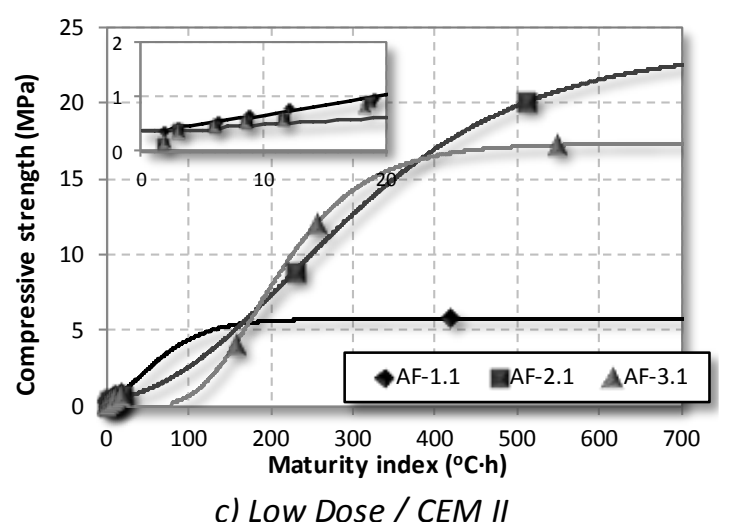

c) Low Dose / CEM II

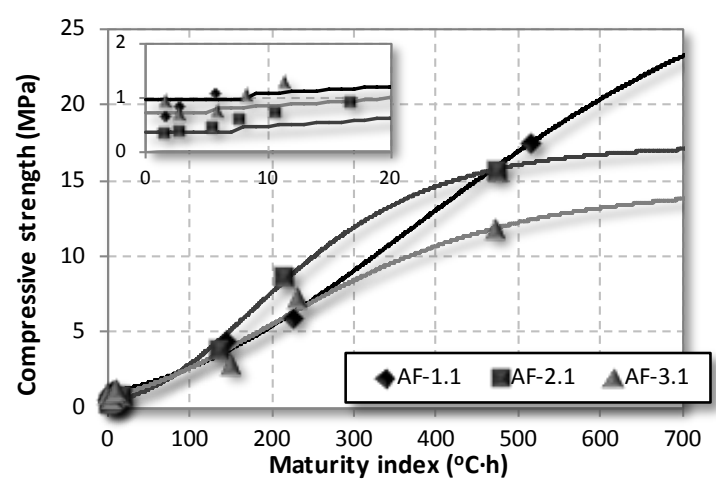

b) High Dose / CEM I
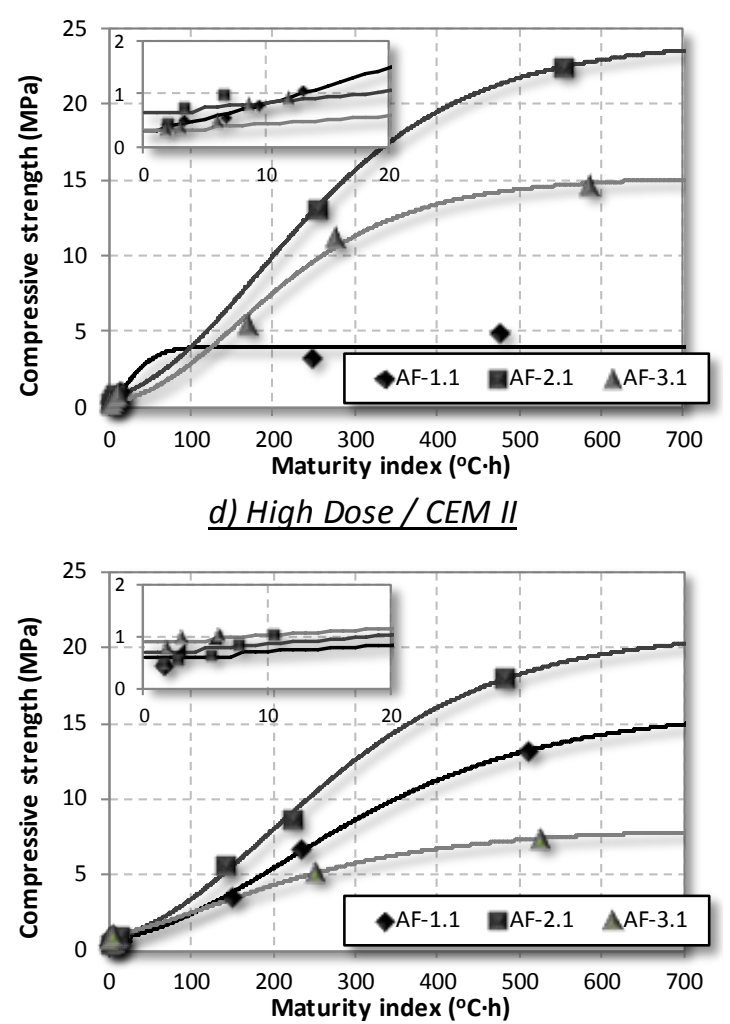

Figure 13- Relationship between the maturity index and the compressive strength 


\subsection{Modelling}

This section presents the results obtained running models 1 and 2 (section 3.4) that were created so that design considerations - such as type of ground support and thickness of the sprayed layer - were taken into account in order to adapt the experimental maturity curves. Firstly, Model 1 was run, introducing and changing the generated heat in order to obtain the same results as the experimental ones obtained with the mix AF-3.1_9_I (Figure 9). Figure 14 shows the results given by TC_L and TC_H, with correlations of 0.996 and 0.993 respectively. The heat generated in the mix due to the chemical reactions of the hydration of the cement combined with the accelerator is thus established.

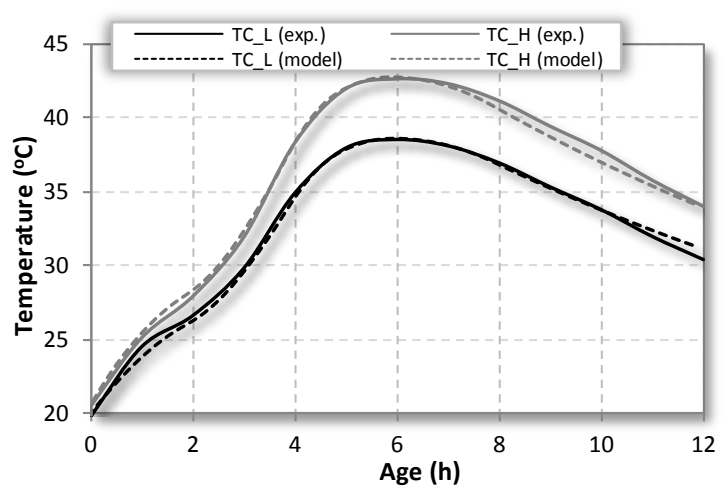

Figure 14- Adjustment model-experimental data

The results obtained from Model 1 were used to run Model 2, estimating new values of maturity indexes, dependant on the type of ground support and the thickness of the sprayed layer. The aim was to adjust the results obtained from spraying a mould of thickness equal to $150 \mathrm{~mm}$ in order to estimate the results gathered in a tunnel with different boundary conditions. The evolutions of temperature of the tunnel lining were thus obtained, as well as the development of the maturity indices with time calculated. Table 10 presents, as an example, the findings when spraying layers of 100 and $150 \mathrm{~mm}$ on clay, together with the results for the concrete sprayed in the mould.

Table 10- Development of maturity index in time $\left({ }^{\circ} \mathrm{C} \cdot \mathrm{h}\right)$

Time $(\mathrm{h}) \quad$ Mould $(150 \mathrm{~mm}) \quad$ Clay $(150 \mathrm{~mm}) \quad$ Clay $(100 \mathrm{~mm})$




\begin{tabular}{cccc}
\hline 0 & 0.00 & 0.00 & 0.00 \\
1 & 24.12 & 45.45 & 24.02 \\
2 & 49.62 & 77.03 & 50.43 \\
3 & 78.80 & 115.16 & 79.30 \\
4 & 113.70 & 160.58 & 112.98 \\
5 & 153.84 & 207.73 & 149.63 \\
6 & 195.91 & 253.39 & 184.27 \\
7 & 238.09 & 296.71 & 215.29 \\
8 & 279.31 & 337.21 & 242.21 \\
9 & 318.96 & 375.48 & 264.84 \\
10 & 357.07 & 412.16 & 283.70 \\
11 & 393.76 & 447.61 & 299.10 \\
12 & 424.24 & 454.79 & 305.54 \\
\hline
\end{tabular}

The results show that reducing the thickness lowered the maturity index significantly. Furthermore, the maturity calculated from samples sprayed into steel moulds underestimates the maturity at $150 \mathrm{~mm}$ thickness. Using these results, it is possible to estimate of the actual in-situ compressive strength by adjusting the results from the mould to fit the results of the lining. To do this, the coordinates of the maturity indices obtained from the mould and from the lining were graphed together. Figure 15 presents the results obtained for various layer thicknesses on clay, limestone and stone ground supports whose thermal properties are indicated in Table 5.
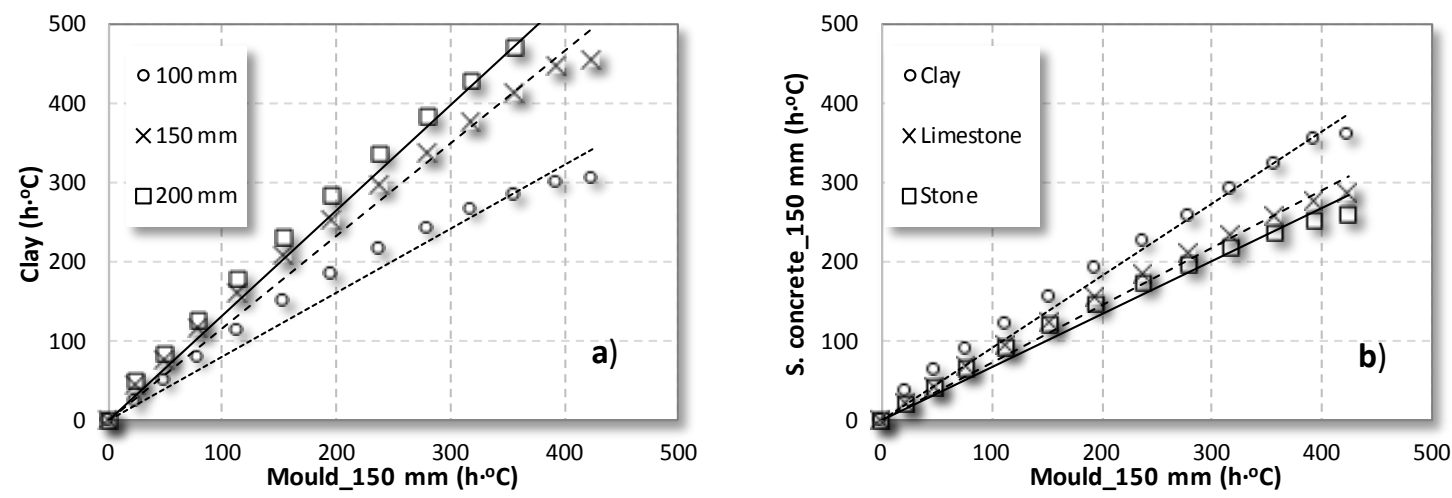

Figure 15- Influence of the thickness a) and the ground support b) on the maturity indices

Notice that an approximately linear relationship is observed between the maturity index calculated in the mould and that in the real condition, regardless of the type of soil and the thickness of the layer. This suggests that in a simplified approach, a constant coefficient may be used to convert the maturity indexes measured in the moulds into the one obtained in the real structure. Such coefficient is given by the slope $\eta$ of the linear regressions from the curves in Figure 15. To apply this coefficient, the minimum maturity index of reference obtained in the 
moulds should be multiplied by $\eta$ to obtain the equivalent minimum maturity index that should be respected in the real structure.

Table 11 presents the $\eta$-parameters obtained for the different boundary conditions together with the correlation coefficients in parenthesis.

\begin{tabular}{|c|c|c|c|}
\hline \multirow{2}{*}{$\begin{array}{c}\text { Thickness } \\
\text { (mm) }\end{array}$} & \multicolumn{3}{|c|}{ Type of ground } \\
\hline & Clay & Limestone & Stone \\
\hline \multirow{2}{*}{100} & 0.809 & 0.726 & 0.672 \\
\hline & $(0.966)$ & $(0.988)$ & $(0.977)$ \\
\hline \multirow{2}{*}{150} & 1.168 & 0.913 & 0.686 \\
\hline & (0.981) & (0.986) & (0.985) \\
\hline \multirow{2}{*}{200} & 1.323 & 0.964 & 0.911 \\
\hline & (0.981) & (0.987) & (0.985) \\
\hline
\end{tabular}

As previously observed, the development of the maturity indexes over time depends on the thickness and the type of ground support, as well as the mix design. Regarding the thickness of sprayed concrete, a decrease involves a reduction of $\eta$, entailing a reduction of the results gathered from the mould, regardless of the ground support type. Furthermore, the thermal characteristics of the ground support affect the value of the parameter $\eta$. Although only three types of ground support were considered, other types may be studied using the thermal model presented in section 3.4. The parameter $\eta$ might also be obtained experimentally from tests performed in moulds and in the real structure.

\section{Maturity method for sprayed concrete}

In order to apply the maturity method to sprayed concrete preliminary and in-situ assessment need to be performed, as illustrated in Figure 16. The preliminary assessment consists of developing the maturity curves according with the requirements of UNE-EN 14488-2 (European Committee for Standarization, 2007) in $150 \mathrm{~mm}$-deep standard moulds. The early compressive strength of the sprayed concrete should be estimated at different times with the penetration needle and stud driving methods. The temperature evolution must also be recorded with in-situ 
thermocouples and a data logger to establish the strength/time relationship. If an approximate prediction of the construction conditions in terms of layer thickness and ground support is available, the $\eta$-parameter would be obtained from the thermal models or experimental studies.

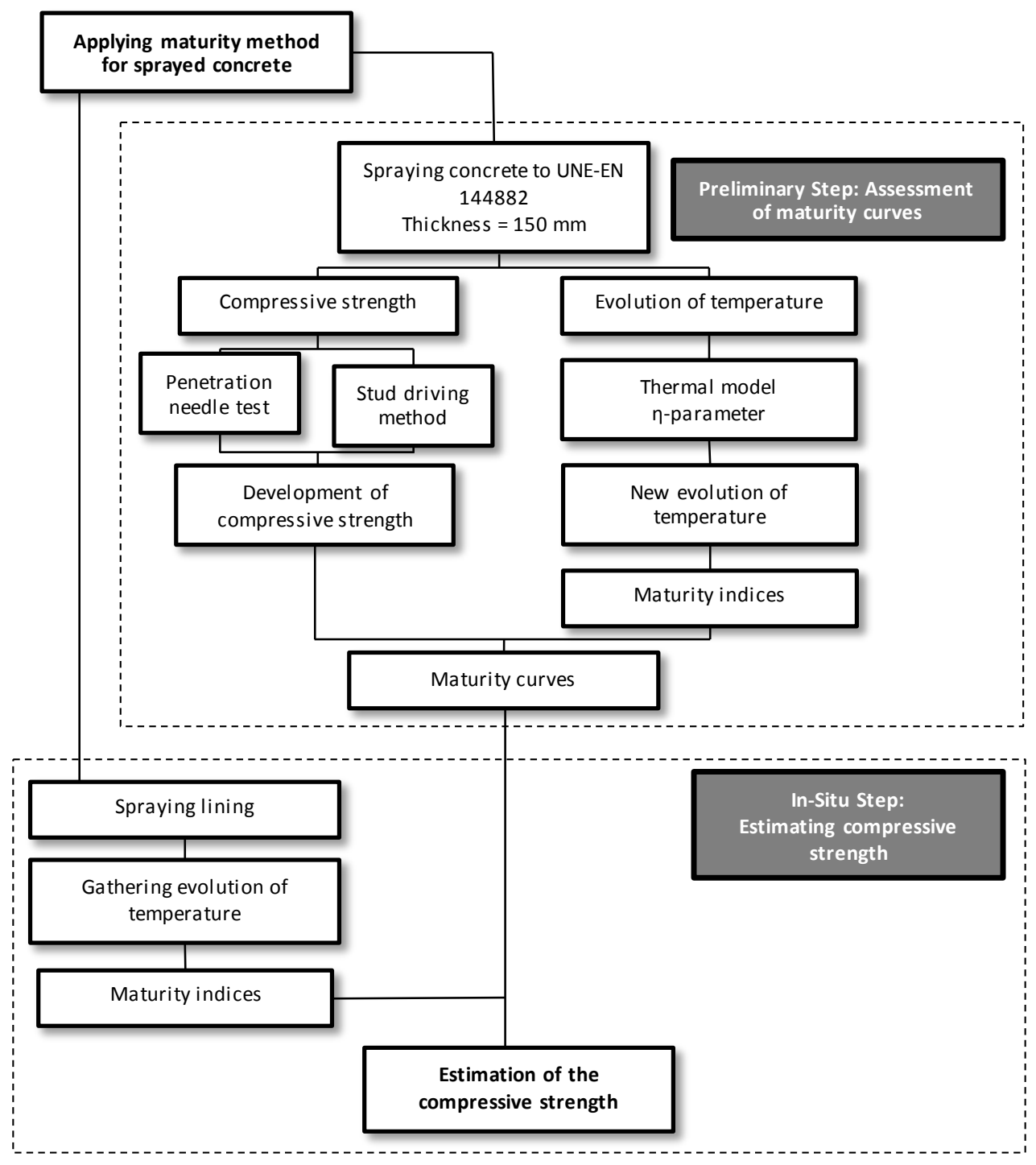

Figure 16- Application of the maturity method to sprayed concrete

The subsequent step requires that thermocouples are carefully placed on the ground and the concrete is sprayed in-situ. A data logger connected to a computer would record the evolution of temperature, which would be automatically used to calculate the maturity index. Then, the compressive strength can be estimated in real time using the $\eta$-parameter, the maturity index measured in the mould and in-situ. This will allow the engineers to make timely decisions as the construction progresses, considering the minimum strength requirements. 


\section{Conclusions}

Based on the results and the analysis conducted, it is clear that the maturity method can be applied to estimate the compressive strength development in sprayed concrete if special considerations are taken into account. In addition to proposing a methodology to apply the method, the following conclusions are drawn from the findings of this study.

- The relationships between the compressive strength development and the maturity index of the mixes with accelerators studied do not fit the Plowman's equation. The poor fit of the experimental results (average $\mathrm{R}^{2}$ of 0.81 ) indicates that the latter is not capable of reproducing well the maturity curves in the mixes tested.

- In order to apply the maturity method for sprayed concrete, the alternative equation (Eq. 3) proposed here should be used since it reproduces well the short-term maturity curves, showing an average $\mathrm{R}^{2}$ of 0.99 . Like in the Plowman's equation, the main parameters should be obtained empirically by curve fitting to the experimental data.

- The maturity curves are affected by the type of accelerator, the dose of accelerator and the type of cement. Therefore, a maturity curve has to be defined for each mix design.

- Design aspects, such as thickness of the sprayed concrete layers and the type of ground support, must be considered in order to adjust the maturity curves obtained experimentally. Such adjustment may be easily performed by applying the $\eta$-parameter obtained through either numerical simulation or experimentally.

\section{Acknowledgments}

The authors of this study would like to thank the Chemical Company Industrias Químicas del Ebro S.A. specifically to Jorge Pérez and Ángel Rueda for their big contribution; the technicians of the Laboratory of Technology of Structures Luis Agulló of the Universitat Politècnica de Catalunya; Ricardo Pelarissi for his contribution in the modelling; and the Universitat 
Politècnica de Catalunya and the Col-legi d'Enginyers de Camins, Canals i Ports de Catalunya for their financial support.

\section{References}

European Committee for Standarization. 'EN 14487-1:2008 'Sprayed concrete - Part 1: Definitions, specifications and conformity'. 2008.

European Committee for Standarization. 'EN 14488-2:2007 'Testing sprayed concrete - Part 2: Compressive strength of young sprayed concrete'. 2007.

Aggoun, S., Cheikh-Zoiaoui, M., Cjikh, N., Duval, R. 'Effect of some admixtures on the setting time and strength evolution of cement pastes at early ages'. Construction and Building Materials 22 (2008) 106110 .

Austin, S. 'Sprayed concrete technology'. s.l., UK: Chapman \& Hall, 1996. ISBN 0419222707.

Austrian Society for Construction Technology. 'Guidelinines for Sprayed Concrete'. 1992.

Carino, N.J., Lew, H.S. 'The maturity method from theory to application'. Proceedings of Structures Congres \& Expositions. 2001.

Carslaw, H.S., J.C. Jaeger. 'Conduction of heat in solids'. Oxford University Press, 1959.

Dimmock, R. 'Sprayed concrete - advanced technologies'. Concrete. 2003. Vol. 3.

Galobardes, I. 'Caracterización de aditivos acelerantes utilizados en proyección de hormigón por vía húmeda'. Master Thesis. Universitat Politècnica de Catalunya. Barcelona Tech., 2010.

Galobardes, I. 'Characterization and control of wet mix sprayed concrete with accelerators'. PhD Thesis. ETSCCP. Universitat Politècnica de Catalunya, 2013.

Galobardes, I. 'Estudio relativo a la caracterización de aditivos acelerantes para hormigón proyectado por vía húmeda'. Minor Thesis. Universitat Politècnica de Catalunya. Barcelona Tech., 2009.

H. Beushausen, M. Alexander, Y. Ballim. 'Early-age properties, strength development and heat of hydration of concrete containing various South African slags at different replacement ratios'. Construction and Building Materials. Vol. 29. 2012.

Julliand, P. 'Early Hydration of Cementitious Systems'. PhD Thesis. ÉCOLE POLYTECHNIQUE FÉDÉRALE DE LAUSANNE, 2009.

Kaszyñska, M. 'Early age properties of high-strength/high-performance concrete'. Cement \& Concrete Composites. Vol. 22. 2002.

Liwu, M., Min, D. 'Thermal behavior of cement matrix with high-volume mineral admixtures at early hydration age'.Cement and Concrete Research 36 (2006) 1992-1998

Neville, 2008. ‘Concrete Technology’. Perasen Education. ISBN 8131705366, 9788131705360. 2008

Plowman, J.M. 'Maturity and the strength of concrete'. Vol. 8. Magazine of Concrete research, 1956.

S. Juan, M. A. 'Los cementos de adición en España del año 2000 al 2005'. Cemento-Hormigón. 2007. 455. 
Scheider, M. et al. 'Sustainable cement production- present and futur'. Cement and Concrete Research. Vol. 41. 2011. 642-650.

Sofi, M., P.A. Mendis, and D. Baweja. 'Estimating early-age in situ strength development of concrete slabs'. Vol. 29. Construction and Building Materials, 2012.

Waller, V., d’Aloïa, L., Cussigh, F., Lecrux, S. 'Using the maturity method in concrete cracking control at early ages’. Cement and Concrete Composites Vol. 26, 589-599. 2004.

Yongjuan Zhang, Xiong Zhang. 'Research on effect of limestone and gypsum on C3A, C3S and PC clinker system'. Construction and Building Materials. Vol. 22. 2008.

Zangerle, D. 'The use of wet mix sprayed concrete'. Tunnels and Metropolises. 1998. Vol. 1 and 2. 